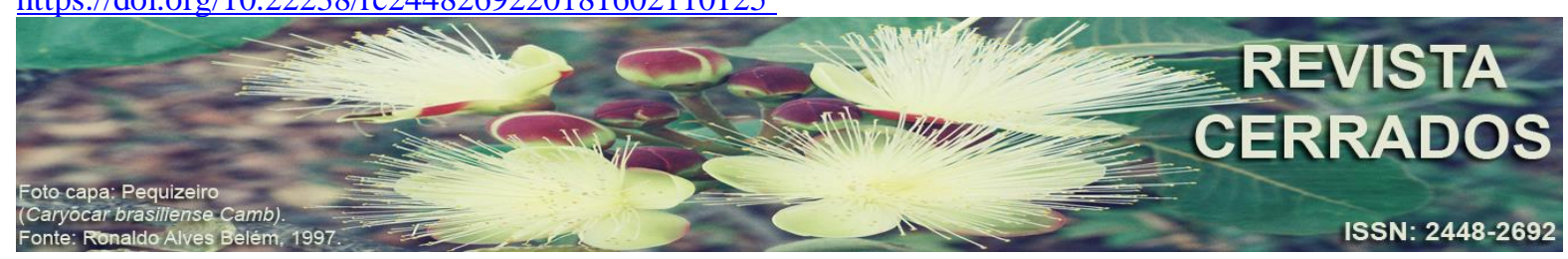

\title{
O MÉTODO REGRESSIVO-PROGRESSIVO COMO POSSIBILIDADE PARA OS ESTUDOS DAS CIDADES MÉDIAS
}

\section{THE REGRESSIVE-PROGRESSIVE METHOD LIKE A POSSIBILITY TO STUDIES OF SIZED-MEDIUM CITIES}

\section{EL MÉTODO REGRESSIVO-PROGRESIVO COMO POSIBILIDAD PARA LOS ESTUDIOS DE LAS CIUDADES MEDIAS}

\author{
Samarane Fonseca de Souza Barros \\ Universidade Federal de Juiz de Fora - UFJF \\ E-mail: 〈samaraneb@gmail.com>.
}

\begin{abstract}
RESUMO
$\mathrm{Na}$ atual realidade urbana brasileira, muito se tem discutido sobre o papel das cidades médias nas regiões e redes urbanas as quais estão alocadas. Ao considerar as cidades médias para além de seu porte demográfico, nota-se uma multiplicidade em suas funções e temporalidades distintas que coexistem, bem como uma série de pares analíticos e dialéticos inerentes ao seu cotidiano. Para isto, propõe com o presente trabalho a análise do método regressivoprogressivo do filósofo Henri Lefebvre como possibilidade para o estudo das cidades médias. Apesar do método ter sido lançado, à priori, como investigação da sociologia rural, outras camadas das ciências sociais vêm se apropriando dele, inclusive a Geografia Urbana.
\end{abstract}

Palavras-chave: Henri Lefebvre. Método regressivo-progressivo. Cidades médias.

\begin{abstract}
In the current brazilian urban reality, much has been discussed about the function of mediumsized cities in the regions and urban networks that are allocated. In considering medium-sized cities beyond their demographic size, there is a multiplicity in their distinct functions and temporalities that coexist, as well as a series of analytical and dialectical pairs in their daily lives. For this, it proposes with the present work the analysis of the regressive-progressive method of the philosopher Henri Lefebvre as a possibility for the study of the medium-sized e cities. Although the method has been launched, first, as an investigation of rural sociology, other layers of the social sciences have been appropriating it, including Urban Geography.
\end{abstract}

Key Words: Henri Lefebvre. Regressive-progressive method. Medium-sized cities.

Licenciada sob Creative Commons (cc) $\mathrm{EY}-\mathrm{HO}-\mathrm{HE}$
Revista Cerrados, Departamento de Geociências e Programa de Pós-Graduação em Geografia (UNIMONTES) 
BARROS, S. F. S.

O método regressivo-progressivo como possibilidade para os estudos das cidades médias

\section{RESUMEN}

En la actual realidad urbana brasileña, mucho se ha discutido sobre el papel de las ciudades medias en las regiones y redes urbanas a las que están asignadas. Al considerar las ciudades medias más allá de su tamaño demográfico, se nota una multiplicidad en sus funciones y temporalidades distintas que coexisten, así como una serie de pares analíticos y dialécticos inherentes a su cotidiano. Para ello, propone con el presente trabajo el análisis del método regresivo-progresivo del filósofo Henri Lefebvre como posibilidad para el estudio de las ciudades medias. A pesar de que el método fue lanzado, a priori, como investigación de la sociología rural, otras capas de las ciencias sociales se vienen apropiando de él, incluso la Geografía Urbana.

Palabras clave: Henri Lefebvre. Método regressivo-progressivo. Ciudades medias.

\section{INTRODUÇÃO}

O presente trabalho teve como principal esforço apreender o método regressivo progressivo do filósofo Henri Lefebvre (1978) como possibilidade para o estudo de cidades médias, tendo como contributo teórico-metodológico, sobretudo, o estado da arte acerca do universo das cidades médias brasileiras na contemporaneidade e sobre os percursos do método em questão.

No que concerne a Geografia Urbana, o método varia a depender do enfoque e objetivo de cada pesquisador. Considerando a complexidade que envolve o conjunto de espaços não metropolitanos no Brasil, o quadro torna-se ainda mais variado, dado que apesar de similaridades que aproximam as cidades médias, cada uma é fruto de um contexto urbanoregional específico, apresentando particularidades que valem ser examinadas.

Muitos geógrafos apropriam-se das teorias, conceitos e temas propostos por Lefebvre para a compreensão do urbano e da cidade, principalmente, considerando o espaço como produto e condição das relações de produção. A partir da análise do cotidiano, o autor busca o entendimento da realidade socioespacial partindo da necessidade de uma análise aprofundada da realidade e das relações sociais de produção, bem como estas se reproduzem e são vitais a hegemonia do capitalismo.

Tornar o cotidiano categoria de análise central possibilita a apreensão de diversos espectros da realidade, para os geógrafos urbanos a análise do cotidiano das cidades vai ao encontro da compreensão de formas, funções e processos que circundam tal realidade. De acordo com Lefebvre (1981), o cotidiano é a dimensão empírica da vida, bem como as 
BARROS, S. F. S.

O método regressivo-progressivo como possibilidade para os estudos das cidades médias

máscaras desta realidade, sendo repleto de dualidades e contradições. Segundo Martins (2000, p.57), "é que no pequeno mundo de todos os dias está também o tempo e o lugar da eficácia das vontades individuais, daquilo que faz a força da sociedade civil, dos movimentos sociais". $\mathrm{O}$ autor continua "se a vida de todo dia se tornou o refúgio dos céticos, tornou-se igualmente o ponto de referência das novas esperanças da sociedade. O novo herói da vida é o homem comum imerso no cotidiano" (MARTINS, 2000, p. 57).

Para a operacionalização dessa tarefa Lefebvre (1978) propõe o método regressivo-progressivo, afim de compreender as formas presentes inteiradas as relações precedentes e ao devir do espaço através de uma descrição profunda e crítica da realidade. Apesar da primeira proposição do método ter se dado na direção da sociologia rural, ele foi incorporado em outras áreas das ciências dada a sua riqueza, cabendo a cada pesquisador tomar as devidas precauções e cuidados na transposição.

Isto posto, o artigo segue estruturado em outras três partes, além desta introdução e das considerações finais. A primeira versará sobre a complexidade das cidades médias contemporâneas, bem como as dualidades inerentes aos seus desenvolvimentos; a segunda tratará o método lefebvriano e, por fim, avançará na articulação entre teoria, método e metodologia.

\section{CIDADES MÉDIAS: CONTRIBUTOS TEÓRICOS}

Refletir sobre as cidades médias na contemporaneidade exige esforços transversais e multiescalares, considerando que os fluxos do padrão capitalista ao qual a rede urbana brasileira está imersa se dão nas mais diferentes direções, intensidades e espaços. Apesar do adjetivo 'média' ser intrínseco - sobretudo, no que tange o senso comum - a dimensões quantitativas, cidades médias neste artigo são consideradas a partir das funções e papéis que desempenham na região e rede as quais estão alocadas.

No Brasil, este conjunto de cidades emerge em um contexto espaço-temporal definido, isto é, a partir da segunda metade do século XX na transição do sistema de produção fordista para a acumulação flexível. Neste momento, a rede urbana era composta por cidades de diversos tamanhos, porém, de baixa articulação entre elas, fazendo com que as cidades médias atuassem como nós de integração na teia de relações urbanas. 
O método regressivo-progressivo como possibilidade para os estudos das cidades médias

As deseconomias de aglomeração, nos moldes descritos por Diniz (1993), em meados da década de 1980 e a tendência dos países subdesenvolvidos a incharem os grandes centros, levou as cidades médias a assumirem, em muito, a função de equilibrar socioeconomicamente a rede urbana, representando "um ponto de difusão da produção e dos valores dos sistemas sócio-econômico de que faz parte" (AMORIM FILHO, 1984, p. 12).

A reordenação e redistribuição do sistema produtivo de maneira mais interiorizada que a precedente, dentre outras razões, almejava a homogeneização dos mercados para garantir novas formas de acumulação e reprodução do sistema capitalista, subordinando novos territórios aos seus interesses (BRANDÃO, 2007). O processo que se percebeu no meio urbano brasileiro, portanto, seguiu padrões de desconcentração, nos parâmetros delimitados por Gottdiener, “[...] desconcentração se refere ao aumento absoluto de população e à densidade de atividades sociais em áreas fora das tradicionais regiões citadinas e dos centros populacionais" (1993, p. 19). Nesta direção, passaram a localizar nas cidades médias uma série de atividades antes restritas às aglomerações metropolitanas (SPOSITO, 2007).

As cidades médias oferecem bens e serviços que atendem as demandas de toda a sua hinterlândia, levando a proeminência do setor terciário na vida econômica destas áreas. De acordo com Sposito (2001, p. 635), as cidades médias em grande medida são delimitadas em razão:

de seus papéis regionais e ao potencial de comunicação e articulação proporcionado por suas situações geográficas, tendo o consumo um papel mais importante que a produção na estruturação dos fluxos que definem o papel intermediário dessas cidades.

Porém, dado o atual contexto da globalização e dos avanços das tecnologias de transporte e comunicação, as relações entre as cidades ocorrem cada vez mais para além de seu espaço imediato. A maior rapidez dos fluxos de capital, mercadorias e pessoas engendrou transformações no espaço de influência das cidades médias, ultrapassando as áreas contíguas, como a zona rural e as cidades menores, ampliando as teias de relação (SPOSITO, 2007).

A fase atual do capitalismo, como indica Brandão (2009), é multifacetada e subordina os diversos espaços, pois "o capital busca se tornar sujeito de todos os processos e transformar tudo em seu mero predicado, incluindo o território" (BRANDÃO, 2009, p. 9). Logo, o capitalismo manifestado em inúmeras telas e por agentes diversos demanda inúmeras escalas e relações possíveis, 
BARROS, S. F. S.

O método regressivo-progressivo como possibilidade para os estudos das cidades médias

Por exemplo, cabe destacar as várias e inusitadas metáforas que foram propostas neste debate, tentando caracterizar as escalas (como relacional, à semelhança das notas musicais; multicamadas articuladas, como nas bonecas russas; variados níveis, como nas escadas; construção constante e modulável, como nos andaimes; etc). (BRANDÃO, 2009, p. 11)

Destarte, a noção e entendimento das cidades médias é permeada pelo desafio interescalar, uma vez que a inserção delas na rede urbana tornou-se muito mais complexa e seus papeis vão além da necessidade de intermediação entre outros núcleos, "nada pode ser explicado apenas numa escala" (SPOSITO, 2011, p.130). A ascensão das formas urbanas não metropolitanas gerou novas dinâmicas e reestruturações socioeconômicas que, por sua vez, criaram novas "relações entre localizações e fluxos que se estabelecem articulando, cada vez mais, diferentes escalas geográficas de produção e estruturação dos espaços urbanos" (SPOSITO, 2004, p. 12).

A diversificação do estudo sobre cidades médias dá-se muito em função de cada uma delas ser oriunda de um "processo de urbanização em contextos econômicos, políticos e sociais heterogêneos em um espaço desigualmente fragmentado e articulado" (CORRÊA, 2007, p.23). A esta fragmentação do espaço e cristalização das particularidades históricas de cada cidade atribui-se, ainda, a diferenciação dos papeis delas na divisão territorial do trabalho.

Sposito (2009) alertou sobre a importância de não colocar o foco, exclusivamente, sobre as cidades médias, pois diferentemente das metrópoles elas são entidades espaciais menos complexas, urge para a autora, portanto, a necessidade de se trabalhar com articulações. Um dos pares analíticos elencados por ela articula as continuidades e descontinuidades, isto é, a relação entre os espaços contíguos e a circulação de fluxos não materiais, como as informações, o que propicia a cidade média o estabelecimento de interações com espaços distantes e descontínuos à região a qual ela pertence. Existe, nesta direção, portanto, uma dialética entre as infraestruturas fixas e a movimentação do capital que são indissociáveis e indispensáveis para a reprodução do capitalismo. De acordo com Brenner (1998, p. 461)

The contradiction between fixity and motion in the circulation of capital - between capital's necessary dependence on territory or place and its space-annithilating tendences - for the chaging scalar organization of capitalism (...) capital necessarily depends upon relatively fixed and immobile territorial infrastrucutures, such as 
BARROS, S. F. S.

O método regressivo-progressivo como possibilidade para os estudos das cidades médias

urban-regional agglomerations and territorial states, which are in turn always organized upon multiple, interwined geographical scales ${ }^{1}$.

Ademais, o par continuidade e descontinuidade e as diferentes interações escalares das cidades médias, as colocam "na encruzilhada das verticalidades e das horizontalidades" (SANTOS; SILVEIRA, 2008, p. 281). Isto é, ao mesmo passo que tecem relações mais dinâmicas e complexas, apresentam também práticas mais corriqueiras e típicas de cidades menores. De acordo com Catelan (2013, p. 18)

as horizontalidades e verticalidades encontram-se nessas cidades, fazendo com que suas funções e papeis sejam reconhecidos, tanto na consolidação de uma rede regional como pela interação com as lógicas da escala nacional e, principalmente, a global.

Isto posto, encontra-se no método regressivo - progressivo proposto por Lefebvre (1978) uma opção de método para a compreensão e análise deste tipo de cidade, uma vez que o autor se depara no meio rural da França dos anos 1950 com uma realidade em que estão presentes complexidades horizontais, ou seja, as diferenças essenciais existentes em estruturas da mesma época e complexidades verticais, referentes a coexistência de formações de épocas e datas diferentes. Vale salientar que, apesar do método ter sido aplicado primeiramente para o meio rural, outros estudos o apropriaram para a análise das cidades, como visto em Ortigoza (2010).

Além disso, o método ainda é válido para o estudo das cidades médias, pois, retomando Sposito (2009) e os pares analíticos, para pensar estes núcleos urbanos faz-se necessário o resgate do antes e depois. Cabe ao pesquisador delimitar o seu recorte temporal para superar os estudos monográficos sobre o presente da cidade e tudo o que ela foi ao longo do tempo. De acordo com a autora, este recorte temporal para o estabelecimento do antes e depois deve marcar algo significativo para a análise daquela cidade,

Quer dizer, qual é o momento em que há um conjunto de dinâmicas, de processos, de acontecimentos, de mudanças de práticas socioespaciais pelos quais se redefinem os papeis daquela cidade no conjunto das cidades, alteram-se as estruturas de organização do seu espaço urbano, enfim, modifica-se o modo como aquela cidade se relaciona com os outros espaços, porque Geografia é sempre o tratamento das

\footnotetext{
1 “A contradição entre fixidez e movimento na circulação do capital - entre a necessária dependência do território ou o lugar e suas tendências de supressão do espaço - para a organização escalar do capitalismo (...) depende necessariamente de infraestruturas territoriais relativamente fixas e imobilizadas, tais como aglomerações urbano-regionais e estados territoriais, que por sua vez são sempre organizados em múltiplas escalas geográficas entrelaçadas" (Tradução da autora).
} 
BARROS, S. F. S.

O método regressivo-progressivo como possibilidade para os estudos das cidades médias

relações espaciais, nunca deve ser apenas localização, a localização é só o começo, mas não é o suficiente, o que está no território é um começo para se pensar, mas é insuficiente para se alcançar uma análise mais abrangente e profunda (SPOSITO, 2009, p. 39).

Sendo assim, se apresentará adiante o método regressivo-progressivo em si e, como este, torna-se uma opção de método - e metodológica - válida para a compreensão de espaços não metropolitanos no Brasil.

\section{O MÉTODO REGRESSIVO-PROGRESSIVO DE HENRI LEFEBVRE}

O método regressivo - progressivo proposto pelo filósofo Henri Lefebvre (1978) tem a sua concepção atribuída a Marx (DUARTE, 2006) e baseia-se em uma análise do presente partindo do atual para o passado para o esclarecimento dos processos em curso e apontamentos para o futuro. De acordo com Lefebvre (1972, p. 30), o conhecimento passa por um "movimento de duplo sentido: regressivo (do virtual ao atual, do atual ao passado) e progressivo (do superado e do terminado, ao movimento que determina aquela conclusão e que anuncia e faz surgir algo novo)". Sendo assim, os fenômenos devem superar a linearidade da sucessão dos fatos e serem compreendidos enquanto processos articulados nas mais diferentes temporalidades.

O método, proposto pelo autor em um primeiro momento como possibilidade para a sociologia rural, está formulado em seu livro De lo rural a lo urbano (LEFEBVRE, 1978) e compreende três momentos de investigação, a saber: o descritivo, o analítico-regressivo e o histórico-genético.

O primeiro momento do método, a etapa descritiva, consiste com a observação do objeto de estudo, com diversas técnicas e embasamentos teóricos que coadjuvem na descrição. A descrição não deve ser baseada apenas na descrição pura e rasa dos fatos, pois isso engendraria uma análise parcial da realidade. O pesquisador deve se apoiar em teorias críticas para a descrição do visível, "cabe ao pesquisador reconstituir, a partir de um olhar teoricamente informado, a diversidade das relações sociais, identificando e descrevendo o que vê" (MARTINS, 1996, p. 21).

O segundo momento do método, o analítico-regressivo, prevê a análise da realidade descrita considerando as contradições e possibilidades, bem como as diferentes temporalidades dos fenômenos encontrados. Para Martins (1996, p. 21): 
BARROS, S. F. S.

O método regressivo-progressivo como possibilidade para os estudos das cidades médias

a realidade é analisada, decomposta. É quando o pesquisador deve fazer um esforço para datá-la exatamente. Cada relação social tem sua idade e sua data, cada elemento da cultura material e espiritual também tem a sua data. O que no primeiro momento parecia simultâneo e contemporâneo é descoberto agora como remanescente de época específica. De modo que no vivido se faz de fato a combinação prática de coisas, relações e concepções que de fato não são contemporâneas.

$\mathrm{Na}$ etapa histórico-genética ou regressiva-progressiva, último momento do método, reencontra-se o presente descrito, retomando as modificações que a estrutura apresenta. Isto é, busca-se a gênese da formação das estruturas, apontando um marco geral de transformação em uma visão holística do processo. É fundamental que se considere a interação das estruturas e a influência das estruturas recentes sobre as precedentes, subordinadas ou integradas às primeiras (LEFEBVRE, 1978). Martins esclarece (1996, p. 22),

\begin{abstract}
Nesse momento regressivo-progressivo é possível descobrir que as contradições sociais são históricas e não se reduzem a confrontos de interesses entre diferentes categorias sociais. Ao contrário na concepção lefebvriana de contradição, os desencontros são também desencontros de tempos e, portanto, de possibilidades. Na descoberta da gênese contraditória de relações e concepções que persistem está a descoberta de contradições não resolvidas, de alternativas não consumadas, necessidades insuficientemente atendidas, virtualidade não realizadas. Na gênese dessas contradições está de fato a gestação de virtualidades e possibilidades que ainda não se cumpriram.
\end{abstract}

As temporalidades desencontradas neste método são coexistentes no espaço, ou seja, embora os fenômenos sejam datados, eles não devem ser identificados e compreendidos a partir da sucessão de etapas históricas e sim de maneira articulada. Nessa última fase do método, apresenta-se uma análise geral a partir do marco de mudança já identificado reencontrando o presente sob a óptica da reprodução das relações de produção. É importante apontar as contradições emergentes que acolitem nas reflexões finais sobre a realidade estudada. Vale salientar que é a partir do marco de mudança delimitado pelo pesquisador que as relações de produção e a reprodução das relações sociais irão ganhar outro sentido e se manifestar de formas distintas no espaço, isto é, o que havia antes e o que há depois desse marco histórico.

Este método é justificado por Lefebvre, pois, para o filósofo o presente visível não esclarece o real, é preciso fazer a regressão para encontrar os marcos reestruturantes. $\mathrm{O}$ método ainda, por associar dialeticamente passado e presente, permite enxergar as contradições do sistema capitalista. Concordando com Ortigoza (2001, p. 22) 
BARROS, S. F. S.

O método regressivo-progressivo como possibilidade para os estudos das cidades médias

Trata-se de reconhecer onde estão o antigo, o novo, o diferente, pois é a relação dialética desses três movimentos que mantém a reprodutibilidade do sistema. $\mathrm{O}$ novo aparece, muitas vezes, como tendência, uma novidade que contém diferentes tempos históricos, mas que ao ser investigado pode nos oferecer os elementos para uma análise que contribua para desvendar a essência da transformação da realidade, descrita no início do trabalho.

Existe no espaço a relação dialética entre rupturas e permanências e nos períodos de transição - ou no marco de mudança - é clarificante a interdependência deste par analítico. Nesses períodos pode se experimentar a vivência em dois espaços simultâneos, o que já foi e o que ainda não é. A partir das formas do velho mundo se tem as condições necessárias para a sua superação. Superação aqui, contudo, não diz respeito ao desaparecimento das velhas formas, estas são conservadas em processo de transformação, ou ainda, ressignificadas pelo presente.

A transducção, nome pelo qual Lefebvre concebe o movimento regressivoprogressivo, constrói o objeto estudado como algo virtual, aberto ao devir, mas ligado a uma prática concreta. A aplicação deste método, portanto, conjectura a construção simultânea de tempos históricos, possibilitando a identificação de descontinuidades espaço-temporais no urgir da história.

A dialética entre ruptura e permanência, conforme Duarte (2006), se torna mais complexa à medida que as diferentes épocas se interpretam, mantendo vínculos recíprocos que alteram a trajetória e os significados do caminhar. O passado é acionado como uma das condições para realização do presente que, por sua vez, pressente o futuro. De acordo com Benjamin (1982, p.59 apud DUARTE, 2006) “cada época não somente sonha a seguinte, como ao sonhá-la a impele a despertar”.

As cidades médias, retomando o exposto, por serem realidades repletas de dualidades, apresentam desencontros entre o tradicional e o moderno intrínsecos a seu espaço, por isso, mais uma vez, o método regressivo-progressivo se torna plausível para a compreensão desta realidade urbana. Alinhar este método ao longo da pesquisa e das etapas a serem desenvolvidas pode coadjuvar na formação de uma compreensão holística de uma dada cidade, bem como na análise da reprodução do sistema de produção vigente e seus desdobramentos sociais. 
BARROS, S. F. S.

O método regressivo-progressivo como possibilidade para os estudos das cidades médias

\section{TEORIA, MÉTODO E METODOLOGIA}

As contradições existentes nas cidades podem revelar momentos distintos da produção do espaço urbano e também possibilidades a serem apreendidas no futuro. Do real ao virtual, o método lefebvriano coadjuva para se alinhar tempos e temporalidades, espaços e espacialidades.

Como alertado por Sposito (2009), considerar o antes e o depois como recorte analítico para o estudo das cidades médias é importante, pois a partir de um evento ou conjunto de eventos a realidade daquele espaço passa por reestruturações. Este parâmetro aproxima-se do marco de mudança proposto por Lefebvre ao passo que nestes momentos é possível notar as diferentes temporalidades impressas na cidade que ora coexistem, ora se desencontram.

A ideia de reestruturação urbana lograda por Sposito (2004, p. 312) diz respeito às profundas modificações regionais de uma dada área. A autora diferencia reestruturação urbana de reestruturação das cidades, ao passo que esta segunda expressão é concernente ao conjunto de transformações a curto ou longo prazo que direcionam a estruturação intraurbana.

Apesar da ascensão dos espaços não metropolitanos, no Brasil, ter se dado na década de 1980, generalizar este momento como marco de mudança para todas as cidades pode ser um problema, pois para algumas delas este período pode não ser tão significativo. As cidades médias, embora tenham características que as equiparem como tal, apresentam singularidades que as tornam únicas, nenhuma cidade é igual a outra. Neste sentido, a leitura e teoria crítica para a análise das cidades médias seguem duas direções: a que busca o que é universal em todas elas no período contemporâneo e o que as distinguem uma das outras, isto é, a particularidade existente em cada realidade.

Isto posto e após ter realizado o estado da arte, bem como o levantamento de dados secundários válidos para a pesquisa a ser desenvolvida, é hora de fazer o trabalho de campo para obter a descrição guiada pelo olhar devidamente tratado pelas leituras e técnicas consultadas, para identificar e descrever o que se vê de maneira crítica e fundamentada. É válido ressaltar que a escolha do banco de dados é um importante passo metodológico, pois delimita a abrangência espacial e temporal do trabalho, uma vez que cada plataforma de informações se vale de um recorte distinto. É importante, portanto, que o banco de dados 
BARROS, S. F. S.

O método regressivo-progressivo como possibilidade para os estudos das cidades médias

coincida com o marco de mudança, para que as informações levantadas coadjuvem para a compreensão do antes e depois.

O trabalho de campo é valioso, porque permite alinhar teoria e prática. Para o estudo das cidades médias, em específico, é importante conciliar os dois eixos já citados: o que é geral ao conjunto e o que é singular de cada uma. A presença de alguns elementos e infraestruturas urbanas, conforme listado em SPOSITO et al. (2007), são importantes para compreensão dos processos de estruturação e reestruturação imbricados à problemática das realidades urbanas não metropolitanas.

Após a visita in loco é importante que se sistematize o que foi visto para ajudar na decomposição da realidade e datação dos fenômenos, como previsto pela etapa analíticoregressiva. A sistematização dos dados é importante, uma vez que possibilita a articulação de instrumentos metodológicos importantes: os quantitativos e os qualitativos. As informações quantitativas não devem ser reduzidas a lógica positiva hegemônica, "tem sempre de que partir para uma base em que a quantificação das informações nos ofereça o primeiro quadro da situação, porque caso contrário nós vamos tratar da parte sem considerar o todo" (SPOSITO, 2009, p. 45). A tabulação dos dados quantitativos e a análise qualitativa do pesquisador podem garantir eficácia na compreensão da temporalidade do objeto estudado.

Por fim, no terceiro e último momento histórico-genético, em que se busca a análise geral a partir do marco de mudança identificado, reencontra-se as desigualdades inerentes ao modo de produção e como elas estão impressas no espaço. Isto é, se investiga de forma ampla e holística como as temporalidades diferentes coexistem e se influenciam reciprocamente. Uma vez que as cidades médias apresentam formas e processos horizontais e verticais, nesta etapa é possível identificar como a descontinuidade se comporta no continuиm da cidade.

As diferentes formas urbanas oriundas do modo de produção capitalista fazem com que os espaços sejam valorizados de diferentes maneiras no decorrer da história a depender, sobretudo, dos avanços das forças produtivas e das relações que delas se originam. Desta maneira,

Esta sociedade urbana é então transformada em uma sociedade produtivista que se desenvolve no mesmo sentido da produção. As relações sociais de produção, ao determinarem esse tempo, acabam produzindo espaços que nos mostram o sentido da reprodução (ORTIGOZA, 2001, p.153 e 154). 
BARROS, S. F. S.

O método regressivo-progressivo como possibilidade para os estudos das cidades médias

O tempo e o espaço das formas urbanas contidas nas cidades médias ampliam as relações de reprodução do capitalismo, obedecendo um padrão de tendência mundial com usos pré-determinados, fazendo com que a cidade seja ao mesmo tempo condição precedente das relações de produção e produto destas mesmas relações. De acordo com Ortigoza (2010, p. 165) “o global só se realiza no lugar (e no cotidiano), porque as relações sociais (mundializadas, novas) têm materialidade no espaço do cotidiano, que é local”. As cidades médias, nessa perspectiva, por apresentarem fluxos globais do sistema econômico vigente devem ser analisadas também na escala do sistema econômico global (SOARES, 1999). A partir da divisão territorial do trabalho então as cidades médias abrigam as sedes de empresas e atendem demandas mais imediatas. Portanto, estes núcleos urbanos oferecem o consumo final da população e o consumo intermediário das empresas inseridas em uma lógica mais ampla. Santos e Silveira (2008, p. 280) colocam que estas cidades

[...] funcionam como entreposto e fábrica, isto é, como depositárias e como produtoras de bens e serviços exigidos por elas próprias e seu entorno [...]; constitui verdadeiros fóruns regionais, um lugar de debate entre preocupações mais imediatas e desígnios mais amplos.

Sendo as cidades algo em constante construção e produção, ou seja, um espaço $a$ devir aberto a transformações, o método lefebvriano permite a construção do objeto virtual e possível a partir de uma realidade concreta e histórica. O método, por sua vez, não deve ser adotado na pesquisa como algo rígido e imutável, ele deve ser capaz de orientar e dar movimento as investigações dos pesquisadores. Entretanto, Ortigoza (2010, p. 178) alerta

É preciso destacar que existe toda uma preparação teórica, desde a forma como se pensa a hipótese e todo o respaldo conceitual da tese em questão, ou seja, todo o projeto tem que estar vinculado ao método, pois é ele que dá a forma de pensar a sociedade, a realidade e o espaço, essa coerência é fundamental.

O organograma 1 abaixo sintetiza a vinculação do método à metodologia. 
BARROS, S. F. S.

O método regressivo-progressivo como possibilidade para os estudos das cidades médias

Organograma 1 - Síntese do método regressivo-progressivo lefebvriano

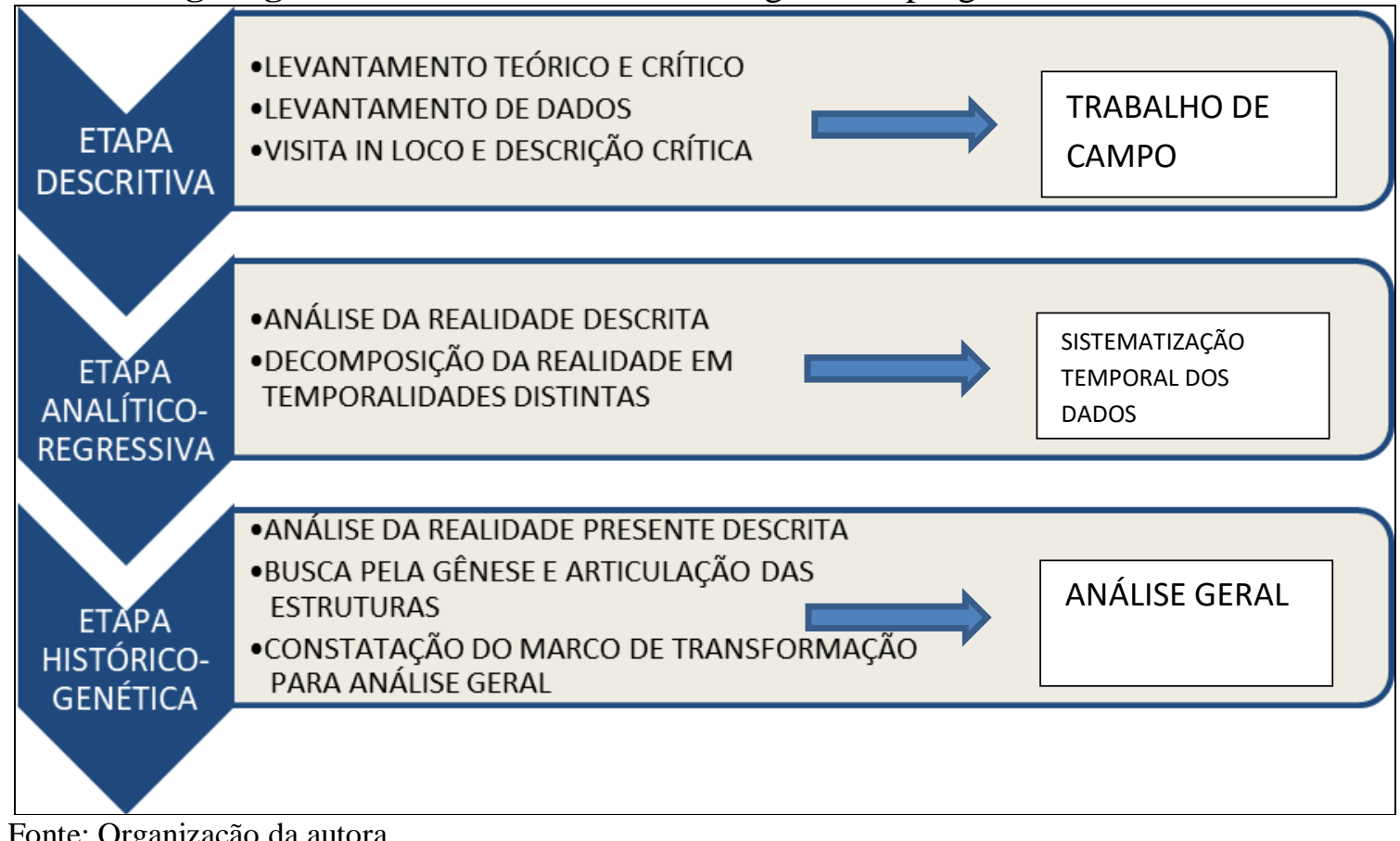

Vinculando a teoria, o método e a metodologia de maneira adequada, acredita ser possível a análise da realidade e do cotidiano das cidades médias a partir das etapas previstas por Lefebvre. A cidade, em sua produção contraditória, apresenta possibilidades para a realidade, bem como proporciona olhares pelos mais variados espectros, sendo a teoria crítica lefebvriana de produção do espaço e do cotidiano como categoria de análise, apenas mais um deles.

\section{CONSIDERAÇÕES FINAIS}

O avanço do estudo das cidades médias na academia brasileira deu-se na direção teórica, mas também, no concernente ao método. Sendo assim, resgatou-se o método regressivo-progressivo de Lefebvre para a compreensão dessas realidades urbanas. As cidades médias apresentam dualidades inerentes a seu cotidiano urbano e o método em questão se mostra plausível ao tentar compreender e justificar estas contradições. A partir da descrição guiada pela teoria crítica e das etapas subsequentes do método é possível traçar um objeto virtual - considerando a cidade um devir - a partir da materialidade do presente em suas interações entre as formas e processos passados, as permanências e rupturas e o antigo e o novo. 
BARROS, S. F. S.

O método regressivo-progressivo como possibilidade para os estudos das cidades médias

O urbano, per se, já apresenta uma gama de processos dinamicamente contraditórios que revelam inúmeras abordagens e metodologias para desvendá-lo. Embora seja um único objeto para todos os campos de ciência que lidam com ele, o urbano pode ser analisado sob os inúmeros vieses metodológicos e opções de método, a depender do trato do pesquisador e de seus objetivos finais. Sendo aqui as cidades médias analisadas enquanto organismos multifacetados e repletos de pares dialéticos, o método regressivo-progressivo é uma inovadora possibilidade de mediação para atingir os fins.

Existem inúmeras temporalidades que coexistem na cidade, bem como tantas realidades oriundas de maneiras de apropriação e padrões culturais diferenciados. Os processos são múltiplos e quase nunca notados "a olhos nus" pelos pesquisadores, gerando esforços teórico-metodológicos para as respectivas compreensões. O método regressivoprogressivo, por sua vez, vai a origem das contradições e das atitudes não efetivadas para apontar o cotidiano das cidades como um objeto rico em possibilidades.

\section{AGRADECIMENTOS}

À Coordenação de Aperfeiçoamento de Pessoal de Nível Superior (CAPES) pela concessão de bolsa de estudos para realização desta pesquisa.

\section{REFERÊNCIAS}

AMORIM FILHO, O. B. Cidades Médias e organização do espaço no Brasil. Revista de Geografa e Ensino, Belo Horizonte, v.2, n.1, jun. 1984, pp. 5-34.

BRANDÃO, C. Território e desenvolvimento: as múltiplas escalas entre o local e o global. Campinas: Editora da Unicamp, 2007.

O necessário diálogo entre a economia política do desenvolvimento e a geografia crítica em momento de crise estrutural do capitalismo. In: XIV Encontro Nacional de Economia Política, 2009, São Paulo. Anais do XIV Encontro Nacional de Economia Política, 2009. v. 1. p. 1-23.

BRENNER, N. Between fixity and motion: accumulation, territorial organization and the historical geography of spatial scales. Envlroment and Planning D: Society and Space, 1998, v. 16, PP. 459-481.

CATELAN, M. J. Heterarquia Urbana: interações espaciais interescalares e cidades médias. São Paulo: Cultura Acadêmica, 2013. 
O método regressivo-progressivo como possibilidade para os estudos das cidades médias

CORREA, R. L. Construindo o Conceito de Cidade Média. In: SPOSITO, Maria Encarnação B. (org). Cidades Médias: Espaço em transição. São Paulo: Expressão Popular, 2007. pp. 2334.

DINIZ, C. C. Desenvolvimento poligonal no Brasil: nem desconcentração nem contínua polarização. Nova Economia, 3 (1), pp. 35-64, 1993.

DUARTE, C. F. A dialética entre permanência e ruptura nos processos de transformação do espaço. In: MACHADO, D. B. P.(Org). Sobre urbanismo. 1 ed. Rio de Janeiro: Viana \& Mosley / Ed. PROURB, 2006.

GOTTDIENER, M. A produção social do espaço urbano. São Paulo: Edusp, 1993.

LEFEBVRE, H. La revolucion urbana. Madri: Alianza Editorial, 1972.

De lo rural a lo urbano. Barcelona: Península, 1978.

Le sens de la marche - Critique de la vie quotidienne III: De la

modernité au modernisme (Pour une métaphilosophie du quotidien). Paris: L'Arche Éditeur Paris, 1981.

MARTINS, J. S. (Org.) Henri Lefèbvre e o retorno à dialética. São Paulo: Hucitec, 1996.

. A sociabilidade do homem simples: cotidiano e história na modernidade anômala. São Paulo: Hucitec, 2000.

ORTIGOZA, S. A. G. O tempo e o espaço da alimentação no centro da metrópole paulista. Tese (Doutorado) - Instituto de Geociências e Ciências Exatas, Universidade Estadual Paulista "Júlio de Mesquita Filho". Rio Claro, 2001.

As possibilidades de aplicação do método de análise regressivoprogressivo de Henri Lefebvre na Geografia Urbana. In: GODOY, P. R. T. (Org). História do pensamento geográfico e epistemologia em Geografia. São Paulo: Editora UNESP; São Paulo: Cultura Acadêmica, 2010. 289 p.

SANTOS, M.; SILVEIRA, M.L. O Brasil: território e sociedade no início do século XXI. Rio de Janeiro: Record, 2008.

SOARES, B. R. Repensando as cidades médias brasileiras no contexto da globalização. Revista Formação, Presidente Prudente, v. 1, n. 6, p. 55-63, 1999.

SPOSITO, M .E .B. As cidades médias e os contextos econômicos contemporâneos. In: SPOSITO, Maria Encarnação Beltrão (org.). Urbanização e cidades: perspectivas geográficas. Presidente Prudente: UNESP/GAsPERR, 2001.

. O chão em pedaços: urbanização, economia e cidades do estado de São Paulo.

Tese (livre docência em geografia) - FCT/UNESP. Presidente Prudente: 2004. 
BARROS, S. F. S.

O método regressivo-progressivo como possibilidade para os estudos das cidades médias

. Cidades médias: reestruturação das cidades e reestruturação urbana. In:

SPOSITO, M. E .B. (Org) Cidades Médias: espaços em transição. São Paulo: Expressão Popular, 2007, pp. 233-253.

. A produção do espaço urbano: escalas, diferenças e desigualdades socioespaciais. In: CARLOS, Ana F. A.; SOUZA,Marcelo J. L. de; SPOSITO, Maria Encarnação B. (Org.). A produção do espaço urbano: agentes e processos, escalas e desafios. São Paulo: Contexto, 2011.

UFPA, 2009.

Para pensar as pequenas e as médias cidades brasileiras. Belém: FASE e

SPOSITO, M. E. B; et al. O estudo das cidades médias brasileiras: uma proposta metodológica. In: Maria Encarnação Beltrão Sposito. (Org.). Cidades médias: espaços em transição. 1ed.São Paulo: Expressão Popular, 2007.

\section{Autora}

Samarane Fonseca de Souza Barros - Possui Graduação em Geografia pela Universidade Federal de Viçosa (UFV). Atualmente cursa o mestrado em Geografia pela Universidade Federal de Juiz de Fora (UFJF), é bolsista CAPES.

Artigo recebido em: 22 de junho de 2018.

Artigo aceito em: 11 de outubro de 2018.

Artigo publicado em: 12 de novembro de 2018. 